Www.jmscr.igmpublication.org

Index Copernicus Value: 79.54

ISSN (e)-2347-176x ISSN (p) 2455-0450

crossref DOI: https://dx.doi.org/10.18535/jmscr/v7i4.16

Journal Of Medical Science And Clinical Research

IGM Publication

An Official Publication of IGM Publication

\title{
Comparative Study of Topical Tacrolimus with Topical Cyclosporine Therapy on Graft Survival and Visual Outcome in Penetrating keratoplasty
}

Authors

\author{
Dr Preeti Rawat ${ }^{1}$, Dr Rajesh Kumar Choudhary ${ }^{2}$, Dr Varun Upadhyay ${ }^{3}$, \\ Dr V Bhaisare ${ }^{3}$, Dr S. Walia ${ }^{3}$, Dr Neetu Kori ${ }^{3}$ \\ ${ }^{1}$ Professor Dept of Ophthalmology MGM Medical College Indore MP India \\ Email: drpreeti.eye@ rediffmail.com Contact no. 9826034458 \\ ${ }^{2}$ PG Resident Dept of Ophthalmology, MGM Medical College Indore MP 452001 India \\ Email: rajeshkumarapril1@gmail.com, Contact no. 8770787743
}

\begin{abstract}
Background: Immunosuppressive therapy is the main postoperative treatment for keratoplasty, as immune mediated graft rejection is now-a-days the most common cause of graft failure after penetrating keratoplasty accounting for at least one-third of failure cases. ${ }^{(1-2)}$ So, the proportion of people who can derive the long term benefit from corneal grafting depends on graft survival rate which is mainly related to post-operative immunosuppressant therapy.

Aim: This study was done to observe the combined Effect of steroid sparing topical drug with routine topical steroid post Penetrating Keratoplasty on graft Rejection, corneal transparency, corneal Vascularization and Visual outcome compared to topical steroid alone.

Method: It was a single-center prospective randomized comparative treatment study completed in the duration of two years. 60 eyes of 60 patients were assigned into three different groups in a randomized manner. All patients underwent therapeutic penetrating keratoplasty by a similar method that involved a donor button that was oversized by $0.5 \mathrm{~mm}$ and 16 bites of interrupted sutures. Along with $1 \%$ prednisolone acetate Group A received $0.03 \%$ Tacrolimus ointment and group-B received $0.1 \%$ cyclosporine in topical form. While group-C received $1 \%$ prednisolone acetate only. Intergroup analysis was done using chi-square test, one way ANOVA test and KruskalWallis test ( $p$ value $<0.05$ was considered significant). Patients whose Keratoplasty was done for fungal corneal ulcer were excluded.

Result: There were no differences among three groups for mean age of donor and recepient, gender predilection, mean graft size, death enucleation interval and enucleation transplantation interval. However variation was noted in recepient's corneal pathology for which keratoplasty was done but it was found to be statistically insignificant. The study revealed that after a mean follow-up of 6 months for each group, addition of Topical Tacrolimus had beneficial effect in getting clear graft (70\%) and hence good visual acuity post operatively, prevention of vascularisation $(60 \%$ of cases showed no vascularsation), less graft rejection 60\%, reversal of graft rejection $75 \%$ and preventing complication like suture infiltrate (50\%), secondary glaucoma (30\%), cataract (25\%), as compared to topical cyclosporine. Although it was found to be statistically insignificant.

Conclusion: Although statistically insignificant, combination of topical tacrolimus with topical prednisolone acetate was found to be better as compared to topical prednisolone alone and combination of topical cyclosporine with topical prednisolone acetate. Hence it can be safely said that post-keratoplasty conventional Immunosuppressant therapy which is Topical Prednisolone Acetate $1 \%$ can be used in conjunction with topical tacrolimus for better graft outcomes. However standard immunosuppressant therapy which is topical steroid could not be replaced by topical cyclosporine or tacrolimus alone in our setup.

Keywords: Penetrating keratoplasty, Tacrolimus, cyclosporine, Graft rejection, Graft failure.
\end{abstract}




\section{Introduction}

Corneal transplantation is a commonly performed solid tissue transplantation procedure. Owing to its recognised immuneprivileged status, corticosteroids usually ensures survival of low risk corneal grafts. However ,high risk grafts (recepients with at least two quadrants of stromal vascularisation, herpes simplex viral keratitis, chemical injury) reported to have higher failure rates ${ }^{(3,4)}$ and with added complications of steroids (like Cataract, Elevated Intraocular pressure, Delayed wound Healing, Infectious keratitis,) lead to conduction of several studies in which steroid sparing drug like Topical Tacrolimus and Topical Cyclosporine were added along with Topical prednisolone acetate $1 \% .^{(5,6)}$ These studies have showed enhanced graft survival in high risk cases.

The final step in modulating the immune system is the same for CSA and tacrolimus, i.e. interfering with the intracytoplasmatic calcineurin system and hence the interleukin IL-2 production, but both drugs manage this in a different manner. Cyclosporine A binds to the intracellular immunophilin cyclophilin (immunophilins are proteins which bind to immunosuppressive drugs). The CSA-cyclophilin complex blocks calcineurincalmodulin-induced phosphorylation of NFAT (nuclear factor of activated $\mathrm{T}$ cells), transcription factor for IL-2 and other early T-cell specific genes $^{(4)}$. In vitro studies have suggested that topical cyclosporine A might possess antifungal properties and this agent has been used as an alternative for reducing inflammation and the subsequent risk of graft failure in setting of fungal graft infection. ${ }^{(7)}$

Tacrolimus binds to the intracellular FKBP-12 (FKbinding protein-12). The tacrolimus-FKBP-12 complex blocks calcineurin calmodulin-induced phosphorylation of the cytoplasmic component of NFAT transcription factor for IL-2 and other "early" genes. Like CSA, tacrolimus is a highly specific inhibitor of lymphocyte activation ${ }^{(8)}$.

So, in this study, we have added topical tacrolimus $0.03 \%$ and topical Cyclosporine $0.1 \%$ to the gold standard treatment for observing and simultaneously comparing the beneficial effect of addition of these drugs (if any) on graft survival and hence visual outcome.

\section{Material and Method}

This was a single-center scientific and ethical committee approved prospective randomized treatment study completed in duration of 2 years (2017-2018). After obtaining written informed consent, participants included in the study underwent complete ophthalmological examination which included visual acuity, history taking, slit lamp biomicroscopy, scrapping, culture and B scan. Patient unwilling to give consent or those diagnosed with clinical fungal ulcer were excluded from the study. After randomly assigning 60 eyes of 60 patients into three different groups all patients underwent penetrating keratoplasty with a similar method that involved a donor button that was oversized by $0.5 \mathrm{~mm}$ and 16 bites of interrupted sutures Corneal transplantation was done with the cornea retrieve in the MK medium, with mean transplantation time being 1-2 day. The three randomly assigned groups were given the following treatment:

Group A: $0.03 \%$ Tacrolimus ointment two times a day plus $1 \%$ topical Prednisolone acetate $2 \mathrm{hrly}$ tapering monthly.

Group B: $0.1 \%$ Cyclosporine four times a day plus $1 \%$ topical Prednisolone acetate $2 \mathrm{hrly}$ then tapering monthly.

Group C:- $1 \%$ topical Prednisolone acetate 2hrly then tapering monthly.

Immunosuppressant therapy was given under the topical and systemic antibiotic coverage of e/d cefazolin 5\%, e/d tobramycin $1.3 \%$ and e/d natamycin 5\% till epithelium was healed. Patients were examined on regular follow up on $1^{\text {st }}$ post operative day, $1^{\text {st }}$ week, $15^{\mathrm{TH}}$ day, 1 month, 3 month and at 6 month and SOS basis. Minimum follow-up period was kept for 6 month. The following were considered as end points of the study: graft failure, death, completion of follow-up and discontinuation of the drug because of side effects. 


\section{Result and Observation}

60 eyes of 60 patients were included in the study. Demographic data of the patients revealed no significant difference in mean age of donor and recepient, gender predilection ,mean graft size, death enucleation interval and enucleation transplantation interval.(table 1). However with respect to donor age and graft clarity $70.5 \%$ graft was clear in the age group of 21-40 years followed by $45 \%$ in age group 41 to 60 but only $54 \%$ of graft were clear when the donor age was more than 60 years (table 2) which suggested that younger the donor age more is the graft clarity. Clinical details of the patients showed most common pathology reported in patients undergoing keratoplasty was corneal opacity, 14 patients were having corneal opacity combined in three groups. In group A maximum patients reported with perforating corneal ulcer, in group B with adherent leucoma and in group $\mathrm{C}$ with corneal ulcer.(Table 3).One way ANOVA test, KruskalWallis test, and chi-square test were employed to compare three groups based on different variables.(p-value $<0.05$ was considered statistically significant).

Pre-operatively maximum patients had visual acuity of PL+ PR - accurate. Post operatively visual acuity was found to be between CF-3 Feet to 6/60 at 6 month follow-up.(table 4)among three groups. In Group A 14 (70 \%) grafts were clear, while $9(45 \%)$ and $10(50 \%)$ in group B and Group C respectively.. Corneal vascularization (deep vessels in peripheral stroma, between 2-4 clock hours) was present in 8 cases $(40 \%)$ in group A, 10 cases $(50 \%)$ in group B and 9 cases $(45 \%)$ in group C. In Group A if vascularization was present it had less severe form compared to other groups (involving less clock hours). In group A, more than 50\% patients showed graft rejection, amongst them the most common mode of graft rejection was endothelial. In group B also more the half patients showed graft rejection common mode being endothelial. Similar findings were reported in group C. Although the time between the onset of rejection symptoms and intervention were similar between groups (6.9 \pm 3.4 and $6 \pm 2.4$ days respectively, $P$ value $=0.34$ ). In group A, topical tacrolimus plus topical steroids reversed the rejection episode in $75 \%$ patients, compared with $50 \%$ cases and $45 \%$ in group B and C respectively. However, the difference was not statistically significant $\quad(\mathrm{P}=0.631)$. Post-op complication like suture infiltrate $(50 \%)$, secondary glaucoma(30\%), cataract $(25 \%)$ was found to be less in Group A patients.(table 5).

Table 1: Demographic details

\begin{tabular}{|l|c|c|c|}
\hline & Group A & Group B & Group C \\
\hline Mean age of recipient (year) & $53.50 \pm 16.43$ & $48.70 \pm 16.18$ & $49.45 \pm 15.30$ \\
\hline Mean Age Of donor (year) & $54.70 \pm 23.497$ & $53.20 \pm 12.898$ & $52.80 \pm 16.816$ \\
\hline Gender Male, Female & 13,7 & 16,4 & 9,11 \\
\hline DET (hour) & $5.27 \pm 0.966$ & $6.30 \pm 1.174$ & $5.60 \pm 1.007$ \\
\hline ETT (hour) & $26.40 \pm 5.789$ & $23.90 \pm 7.354$ & $23.30 \pm 7.056$ \\
\hline Donor button size (mm) & $8.125 \pm 0.6042$ & $8.050 \pm 0.5596$ & $8.150 \pm 0.5642$ \\
\hline
\end{tabular}

Table 2: Donor age and graft clarity

\begin{tabular}{|c|c|c|c|c|c|c|c|c|c|}
\hline \multirow{2}{*}{$\begin{array}{l}\text { Age of } \\
\text { donor } \\
\text { (in } \\
\text { years) }\end{array}$} & \multicolumn{3}{|c|}{ Group A } & \multicolumn{3}{|c|}{ Group B } & \multicolumn{3}{|c|}{ Group C } \\
\hline & $\begin{array}{l}\text { Clear }(\% \\
\text { within } \\
\text { age } \\
\text { group) }\end{array}$ & $\begin{array}{c}\text { Hazy } \\
\text { (\% within } \\
\text { age group) }\end{array}$ & $\begin{array}{l}\text { Opaque } \\
\text { (\% within } \\
\text { age } \\
\text { group) }\end{array}$ & $\begin{array}{c}\text { Clear } \\
\text { (\% within } \\
\text { age } \\
\text { group) }\end{array}$ & $\begin{array}{l}\text { Hazy (\% } \\
\text { within } \\
\text { age } \\
\text { group) }\end{array}$ & $\begin{array}{l}\text { Opaque } \\
\text { (\% within } \\
\text { age } \\
\text { group) }\end{array}$ & $\begin{array}{c}\text { Clear } \\
\text { (\% within } \\
\text { age } \\
\text { group })\end{array}$ & $\begin{array}{c}\text { Hazy } \\
\text { (\% within } \\
\text { age group) }\end{array}$ & $\begin{array}{c}\text { Opaque (\% } \\
\text { within age } \\
\text { group) }\end{array}$ \\
\hline $2-20$ & $0(0 \%)$ & $0(0 \%)$ & $0(0 \%)$ & $0(0 \%)$ & $0(0 \%)$ & $0(0 \%)$ & $0(0 \%)$ & $0(0 \%)$ & $0(0 \%)$ \\
\hline $21-40$ & $8(88.9 \%)$ & $1(11.1 \%)$ & $0(0 \%)$ & $3(75 \%)$ & $1(25 \%)$ & $0(0 \%)$ & $1(25 \%)$ & $2(50 \%)$ & $1(25 \%)$ \\
\hline $41-60$ & $2(100 \%)$ & $0(0 \%)$ & $0(0 \%)$ & $3(37.5 \%)$ & $4(50 \%)$ & $1(12.5 \%)$ & $4(40 \%)$ & $6(60 \%)$ & $0(0 \%)$ \\
\hline$>60$ & $4(44.4 \%)$ & $5(55.6 \%)$ & $0(0 \%)$ & $3(37.5 \%)$ & $\begin{array}{c}5 \\
(62.5 \%)\end{array}$ & $0(0 \%)$ & $5(83.3 \%)$ & $0(0 \%)$ & $1(16.7 \%)$ \\
\hline
\end{tabular}


Table 3 Recipient Corneal pathology

\begin{tabular}{|l|c|c|c|c|}
\hline \multirow{2}{*}{ Diagnosis } & Group A & Group B & Group C & Total \\
\cline { 2 - 4 } & $\begin{array}{c}\text { No. of Patients } \\
\text { (\% within group) }\end{array}$ & $\begin{array}{c}\text { No. of Patients } \\
\text { (\%within group) }\end{array}$ & $\begin{array}{c}\text { No. of Patients } \\
(\% \text { within group) }\end{array}$ & \\
\hline Adherent leucoma & $2(10 \%)$ & $7(35 \%)$ & $3(15 \%)$ & 12 \\
\hline Corneal opacity & $5(25 \%)$ & $4(20 \%)$ & $5(25 \%)$ & 14 \\
\hline Aphakic bullous keratopathy & $0(0 \%)$ & $1(5 \%)$ & $0(0 \%)$ & 1 \\
\hline Graft failure & $2(10 \%)$ & $3(15 \%)$ & $1(5 \%)$ & 6 \\
\hline Corneal ulcer & $2(10 \%)$ & $4(20 \%)$ & $6(30 \%)$ & 12 \\
\hline Perforating corneal ulcer & $7(35 \%)$ & $0(0 \%)$ & $4(20 \%)$ & 11 \\
\hline Anterior staphyloma & $1(5 \%)$ & $1(5 \%)$ & $1(5 \%)$ & 3 \\
\hline Corneal degeneration & $1(5 \%)$ & $0(0 \%)$ & $0(0 \%)$ & 1 \\
\hline Total & $20(100 \%)$ & $20(100 \%)$ & $20(100 \%)$ & 60 \\
\hline
\end{tabular}

Table 4 Inter group comparison of pre-operative and post-operative vision of study participants in group A, $\mathrm{B}$ and $\mathrm{C}$.

\begin{tabular}{|c|c|c|c|c|c|c|}
\hline & \multicolumn{2}{|c|}{ Group A } & \multicolumn{2}{|c|}{ Group B } & \multicolumn{2}{|c|}{ Group C } \\
\hline & $\begin{array}{c}\text { Pre- } \\
\text { operative }\end{array}$ & $\begin{array}{c}\text { Post- } \\
\text { operative }\end{array}$ & $\begin{array}{c}\text { Pre- } \\
\text { operative }\end{array}$ & $\begin{array}{c}\text { Post- } \\
\text { operative }\end{array}$ & $\begin{array}{c}\text { Pre- } \\
\text { operative }\end{array}$ & $\begin{array}{c}\text { Post- } \\
\text { operative }\end{array}$ \\
\hline $\mathrm{PL}+\mathrm{ve}$ & 12 & 2 & 11 & 4 & 9 & 3 \\
\hline CF 1feet & 1 & 0 & 3 & 1 & 4 & 0 \\
\hline CF2feet & 3 & 2 & 3 & 0 & 4 & 4 \\
\hline CF 3feet & 1 & 5 & 0 & 6 & 1 & 2 \\
\hline $1 \backslash 60$ & 2 & 1 & 0 & 1 & 1 & 0 \\
\hline 2160 & 1 & 2 & 1 & 0 & 1 & 0 \\
\hline 3160 & 0 & 0 & 2 & 3 & 0 & 1 \\
\hline 4160 & 0 & 0 & 0 & 1 & 0 & 2 \\
\hline $5 \backslash 60$ & 0 & 2 & 0 & 1 & 0 & 1 \\
\hline $6 \backslash 60$ & 0 & 2 & 0 & 1 & 0 & 5 \\
\hline $6 \backslash 18$ & 0 & 1 & 0 & 1 & 0 & 0 \\
\hline 6136 & 0 & 3 & 0 & 1 & 0 & 2 \\
\hline p value f $^{7}$ & \multicolumn{2}{|c|}{$0.000 *$} & \multicolumn{2}{|c|}{$0.000 *$} & \multicolumn{2}{|c|}{$0.000^{*}$} \\
\hline
\end{tabular}

$*$ p value $<0.05$ was considered statistically significant., ¥Kruskalwallis test +

Table 5 Post operative Complications in Different Groups in 6 month follow up

\begin{tabular}{|l|c|c|c|c|c|c|}
\hline \multirow{2}{*}{ Postoperative Complications } & \multicolumn{2}{|c|}{ Group A } & \multicolumn{2}{c|}{ Group B } & \multicolumn{2}{c|}{ Group C } \\
\cline { 2 - 7 } & No. & $\%$ & No. & $\%$ & No & $\%$ \\
\hline Epithelial Bullae Formation & 7 & $35 \%$ & 8 & $40 \%$ & 9 & $45 \%$ \\
\hline Iritis & 4 & $20 \%$ & 5 & $25 \%$ & 4 & $20 \%$ \\
\hline Suture infiltration & 11 & $55 \%$ & 16 & $80 \%$ & 16 & $80 \%$ \\
\hline Epithelial defect & 11 & $55 \%$ & 12 & $60 \%$ & 16 & $80 \%$ \\
\hline Cataract & 5 & $25 \%$ & 7 & $35 \%$ & 8 & $40 \%$ \\
\hline $\begin{array}{l}\text { Secondary glaucoma NCT } \\
(>21)\end{array}$ & 7 & $35 \%$ & 10 & $50 \%$ & 11 & $55 \%$ \\
\hline Graft rejection & 12 & $60 \%$ & 14 & $70 \%$ & 13 & $65 \%$ \\
\hline Anterior synechy & 4 & $20 \%$ & 3 & $15 \%$ & 3 & $15 \%$ \\
\hline Vascularization & 8 & $40 \%$ & 10 & $50 \%$ & 9 & $45 \%$ \\
\hline
\end{tabular}

\section{Discussion}

In our study we found that combination of topical tacrolimus with topical prednisolone acetate was better as compared to topical prednisolone alone and combination of topical cyclosporine with topical prednisolone acetate but it was statistically insignificant. In this study there was no significant differences among three groups for mean age of recipient and gender predilection which collobrated with the study of Mohammad; reza Sedghipour 2007 9) who concluded that age or gender had no statistically significant effects on the penetrating keratoplasty outcome. However with respect to findings of donor age and graft clarity our finding of younger the age more is the graft clarity was supported by Mark J. Mannis, Edward J. Holland, 
MD, Robin L (2013) who concluded that graft failure was significantly associated with high donor age. ${ }^{(10)}$ The mean DET (Death Enucleation Interval) varied from 5.27 to 6.30 amongst three groups, being highest in group B $(6.30 \pm 0.966)$. This interval was in corrobration with the Eye Bank Association of America (1990-92), who recommended enucleation of eyes within 8 hours of death for better graft outcomes. In terms of ETT (Enucleation transplantation time) no significant variation was observed among three groups. The most common recepient pathology for indication of keratoplasty was post inflammatory scarring (43.33\%) which correlated with the study of Dandona et al. (1997) who reported highest cumulative indication for penetrating keratoplasty was post inflammatory scarring $(28.1 \%)$ followed by failed graft $(17.1 \%)$, active infectious keratitis $(12.2 \%){ }^{(11)}$ Group A (topical tacrolimus plus topical prednisolone acetate) showed better results post operatively at 6 month follow-up than other two groups in terms of graft clarity $(70 \%)$ and hence good visual acuity post operatively, prevention of vascularisation $(60 \%$ of cases showed no vascularsation), less graft rejection $60 \%$, reversal of graft rejection $75 \%$ and preventing complication like suture infiltrate $(50 \%)$, secondary glaucoma(30\%), cataract $(25 \%)$. These findings were supported by the study carried out by Joseph A, Raj D et al 2006 who founded Tacrolimus as a relatively safe and effective drug in reducing rejection and prolonging graft survival in patients with high-risk keratoplasty. Otavio A Magalhaes et al (2013) also concluded that Topical $0.03 \%$ tacrolimus was effective in preventing irreversible rejection in patients with high-risk corneal transplantation without increasing IOP. ${ }^{(12)}$ In our study variation was observed in graft clarity in comparison to recipient corneal pathology (cases with without any infected cause found to be more clear ), although it was found to be statistically insignificant.

\section{Conclusion}

Post-keratoplasty Immunosuppressant therapy that is Topical Prednisolone Acetate 1\% cannot be replaced by Topical Tacrolimus $0.03 \%$ ointment and Topical
$0.1 \%$ Cyclosporine in our setup. However, data showed addition of Tacrolimus has beneficial effect in getting clear graft, reversal of graft rejection and Preventing complication like suture infiltrate, secondary glaucoma, severe grade of Vascularization, cataract though difference was statistically insignificant $(\mathrm{P}$ value $>0.05)$.

\section{References}

1. Polack, F.M., 1973. clinical and pathological aspects of corneal graft rejection. Trans Amer Acad Ophthalmol., 77: 418-431

2. Khodadoust, A.A.,1973. The allograft rejection reaction, the leading cause of late failure of clinical corneal graft in corneal graft failure. Ciba Symposium, Elsevier, Amesterdam, 151-64.

3. Hill JC. Immunosuppression in corneal transplantation. Eye 1995;9(Pt 2):247-53.

4. Hill JC. Systemic cyclosporine in high-risk keratoplasty. Short- versus long-term therapy. Ophthalmology 1994;101:128-33

5. Mills RA, Jones DB, Winkler CR, et al. Topical FK-506 prevents experimental corneal allograft rejection. Cornea 1995;14:157-60.

6. Perry HD, Donnenfeld ED, Acheampong A, et al. Topical cyclosporine $A$ in the management of postkeratoplasty glaucoma and corticosteroid-induced ocular hypertension $(\mathrm{CIOH})$ and the penetration of topical $0.5 \%$ cyclosporine A into the cornea and anterior chamber. Clao J 1998;24:15965

7. Perry HD, Doshi SJ, Donnenfeld ED, et al. Topical cyclosporine $\mathrm{A}$ in the management of Therapeutic Keratoplasty for mycotic Keratitis.

8. Woodle ES, Thistlethwaite JR, Gordon JH for the FK506 Kidney Transplant Rescue Study Group (1996) A multicenter trial of FK506 (tacrolimus) therapy in refractory acute renal allograft rejection. Transplantation 62:594-599. 


\section{JMSCR Vol||07||Issue||04||Page 78-83||A pril}

9. Mohammad Reza Sedghipour et al. Incidence of and Risk Factors for Increased Intraocular Pressure After Penetrating Keratoplasty. March 2010; volume 29 - (3) - 278-282.

10. Mark J. Mannis, Edward J. Holland, MD, Robin L Effect of Donor Age on Penetrating Keratoplasty for Endothelial Disease. Cornea: December 2013 Volume 120

11. Lalit Dandona. Causes of corneal graft failure in India. Indiana Ophthalmol 1998;46:49 - 52.

12. Magalhaes OA, Marinho DR, Kwitko STopi cal $0.03 \%$ tacrolimus preventing rejection in high-risk corneal transplantation: a cohort study British Journal of Ophthalmology 2013;97:1395-1398. 